\title{
Is there an impatience genotype leading to non-adherence to long-term therapies?
}

\author{
G. Reach
}

Received: 27 December 2009 / Accepted: 8 March 2010/Published online: 21 April 2010

(C) Springer-Verlag 2010

\begin{abstract}
In chronic diseases such as diabetes, adherence to therapy aims to preserve health, which is a long-term objective, whereas non-adherence tends to present an immediate 'reward'. We propose that non-adherence, like addiction, is at least in part due to the fact that, for physiological, and maybe genetic reasons described in a new field, neuroeconomics, a number of people have a taste for the present rather than the future. Thus, for 'impatient patients' it is natural not to adhere to therapeutic prescriptions that share the characteristic of being future-oriented. This hypothesis may apply to any disease requiring long-term therapy.
\end{abstract}

Keywords Adherence - Chronic diseases ·

Impatience genotype $\cdot$ Neuroeconomics

\section{Abbreviations \\ fMRI Functional magnetic resonance imaging \\ MPR Medication possession ratio}

\section{Introduction}

Non-adherence is a major issue in contemporary medicine: in a recent report, the WHO claimed that increasing the

\section{G. Reach $(\square)$}

Service d'Endocrinologie, Diabétologie, Maladies Métaboliques, Hôpital Avicenne APHP,

125 route de Stalingrad,

93000 Bobigny, France

e-mail: gerard.reach@avc.aphp.fr

G. Reach

Université Paris 13,

CRNH-IdF,

EA 3412 Bobigny, France effectiveness of adherence interventions may have a far greater impact on health than any improvement in specific medical treatments' [1]. A study in diabetes demonstrated a negative correlation $(p<0.001)$ between an index of adherence, the medication possession ratio (MPR, the ratio of the total days of the supply of medication dispensed divided by the number of days of the evaluation period) and mean $\mathrm{HbA}_{1 \mathrm{c}}$ level in 655 and 1,013 patients treated with metformin or sulfonylureas, respectively; specifically, $\mathrm{HbA}_{1 \mathrm{c}}<7.0 \%$ was clearly observed in patients with MPR $\geq 1$, suggesting that if patients simply adhered to their medication, diabetes would be controlled in most of them [2]. Another study, in 249 diabetic patients [3], showed that mean adherence 1 year after initiating therapy was $81 \%$, and that $65 \%$ had good adherence (MPR $>80 \%$ ). Here again, an inverse relationship existed between adherence and $\mathrm{HbA}_{1 \mathrm{c}}$; after controlling for baseline $\mathrm{HbA}_{1 \mathrm{c}}$ and regimen, each $10 \%$ increase in adherence was associated with a $0.1 \%$ decrease in $\mathrm{HbA}_{1 \mathrm{c}}(p=0.0004)$. In a multivariate analysis [4], non-adherence remained significantly associated with increased risks for all-cause hospitalisation $(p=0.001)$ and for all-cause mortality $(p=0.001)$. Finally, adherence to diabetes therapy was found to be associated with a decrease in healthcare costs, mostly through a decrease in hospitalisation $[5,6]$.

A recent study evaluated non-adherence in seven chronic diseases: hypertension, hypothyroidism, type 2 diabetes, seizure disorders, hypercholesterolaemia, osteoporosis and gout [7]. Sample sizes ranged from 4,984 patients for seizure disorders to 457,395 for hypertension. MPR $>80 \%$ during the first year of therapy (good adherence) was observed in $72.3 \%, 68.4 \%, 65.4 \%, 60.8 \%, 54.6 \%, 51.2 \%$ and $36.8 \%$ of patients, respectively, for the seven disorders. Interestingly, the lowest adherence was observed in patients with gout, a disease which can take the form of a painful 
crisis. More surprisingly, a recent study showed that use of non-steroidal anti-inflammatory drugs in the year prior to urate-lowering drug initiation (suggesting the occurrence of a crisis), was a significant predictor (OR 1.15, 95\% CI $1.00-1.31$ ) of poor adherence to subsequent gout therapy [8]. These observations contradict the common view that non-adherence is especially frequent in 'silent' diseases such as diabetes. Younger age ( $<60$ years) has also been associated with lower adherence for all diseases except seizure disorders [7], suggesting that the chronic character of the disease, i.e. its potential future duration, is more important than the fact that it may be painful.

The aim of this article is to propose a hypothesis explaining this effect of time on adherence to long-term therapies. The point I wish to make is that people are nonadherent when they are unable to give priority to their future. The choice between adherence and non-adherence can indeed be seen as a choice that the patient will have to make, day after day, between a larger delayed reward for adherence (prevention of complications) and a smaller but more immediate reward for non-adherence, e.g. an extra portion of cake, the forbidden cigarette, avoiding the boring task of looking for the tablets, avoiding the side effects of the medication. There is therefore a paradox of non-adherence to long-term therapies, in that non-adherent individuals prefer a reward that is more immediate but smaller.

\section{Neuroeconomics and the force of our desires}

Neuroeconomics, a new field of study, may shed some light on this puzzling behaviour [9]. Everyday experience indicates that the force of our desire for a reward increases strongly, and asymptotically, as we approach its delivery (think of the night before you take possession of a new car). The function describing this increase is indeed hyperbolic [10]: Fig. 1a shows how individuals describe the residual value of a given amount of money (e.g. US\$1,000) if it is offered, not immediately, but in 1, 6, 12, 60 months, etc. The discounting rate is not constant, being more important during the first months. For this reason, a hyperbolic function $(V=1 /[1+k \mathrm{t}])$ gives a better fit than an exponential function (Fig. 1b). Figure 1c shows two curves with different values of $k$ and Fig. 1d represents Fig. 1c after its rotation around a vertical axis. The two curves on Fig. 1d can be viewed as a representation of the change in the respective forces of the desire, increasing more abruptly in the case of the high $(0.05) k$ value. Thus, this variable,
Fig. 1 a Distribution of individual certain-immediate amounts equivalent to US $\$ 1,000$ with various delays. b Median amount of certain-immediate money equivalent to US $\$ 1,000$ with various delays (data from panel a). The solid line is the best-fitting hyperbolic function $\left[V=V_{0} /(1+k t) ; k=0.014\right.$,

$\left.V_{0}=1,000\right]$; the dashed line is the best-fitting exponential function $\left(V=V_{0} \mathrm{e}^{-\mathrm{kt}}\right)$. c Two discounting curves with the corresponding $k$ value of the hyperbolic equation $[V=1 /(1+k t)]$. Solid line, $k=0.01$; dashed line, $k=0.05$.

d This is panel $\mathbf{c}$ after rotation around a vertical axis. Modified with permission from Rachlin et al. [10]. Copyright (1991) by the Society of the Experimental Analysis of Behavior, Inc.

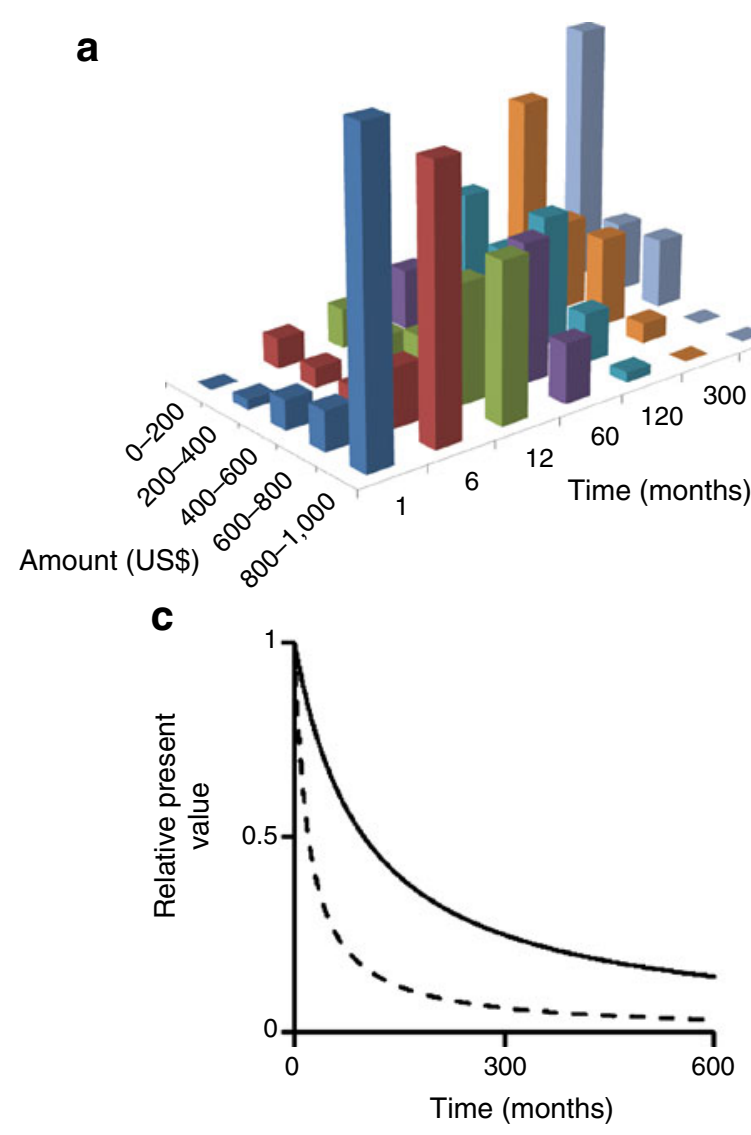

b
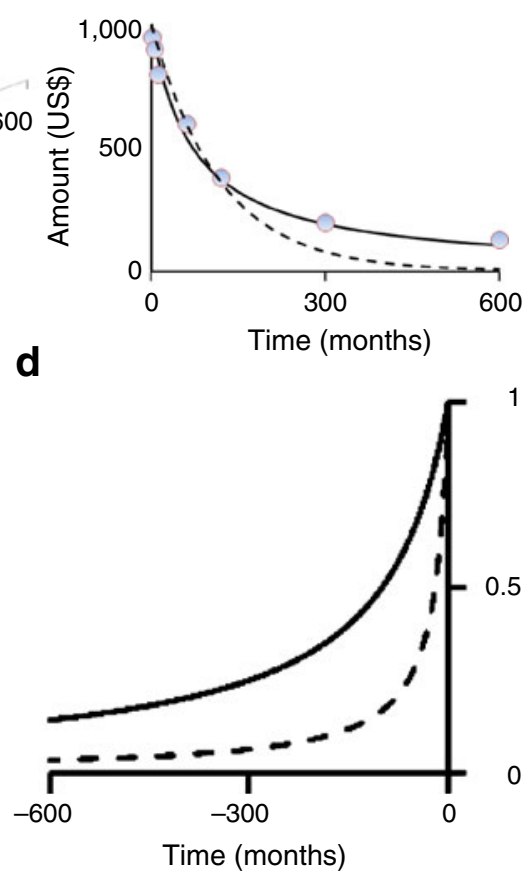
which can be determined through this monetary scenario, represents an empirical evaluation of impatience. Studies using analogous experimental procedures in birds and animals [11] demonstrated that pigeons are more impatient than rats, having a higher $k$ value $(0.77 / \mathrm{s}$ vs $0.16 / \mathrm{s})$. By comparison with these values expressed as per second, the value of $k$ in humans is expressed per month, indicating a huge development of patience. In children, the ability for delaying gratification appears in the preschool years, and 4-year-old children having this type of future-oriented self control were found to develop into more cognitively and socially competent adolescents, coping better with frustration and stress [12].

It is therefore possible to quantify the level of impulsivity of human individuals: some are more impatient, which means that people discount the future to a greater or lesser extent [13]. This level of impulsivity is associated with some pathogenic behaviours; the $k$ value of the hyperbolic function describing impulsivity during a monetary choice has been found to be higher in different forms of addiction (smoking [14], alcohol habits [15], addictions to various kinds of drugs [16]), and, recently, in depressive patients [17] and obese women [18].

Studies using brain functional magnetic resonance imaging MRI (fMRI) showed that the degree of impulsivity manifested during a monetary choice can be seen as the result of the activity of two competing systems: choices for delayed outcomes are related to the prefrontal cortex, while choices for immediate outcomes are related to the limbic brain regions $[19,20]$. The degree of impulsivity was found to be linked to polymorphisms of catechol- $O$-methyl-transferase (COMT) [20] or monoamine oxidase [21], two enzymes that control the cerebral level of serotonin and dopamine. Recently, a brain fMRI study performed in children and adolescents found an association of this polymorphism of COMT with the cortical thickness of a right prefrontal region intimately linked to key aspects of cognition [22].

Impatience may therefore have a genetic basis. It may represent a primitive inherited trait, having had at some time an evolutionary advantage: as claimed by Elster, 'in the animal realm the general mechanism of natural selection creates a presumption of myopia' [23]. It is tempting to speculate that an 'impatience genotype' may now have pathogenic consequences - and may even come to replace the thrifty genotype hypothesis [24] in the pathogenesis of diabesity.

More recently in evolutionary history, the development of the prefrontal cortex may have been associated with the development of an ability to delay rewards. Interestingly, it was recently shown that the activation of the prefrontal cortex during a monetary choice is independent of the fact that the money gain is real or fictional; the authors of this study speculated that 'this makes sense from an evolutionary basis as humans often have to consider future outcomes to make plans important to survival. It would be difficult to imagine evolutionary pressure that would result in differing neurobehavioral processes for future events that occur vs those that do not' [25].

This neuroeconomical description of the force of the desire can explain how people decide between the two competing, smaller-sooner and larger-later, rewards of nonadherence and adherence, and opt for the first: for example by consuming their dessert, even if they had decided when entering the restaurant that they would follow their diet (Fig. 2). This is a direct consequence of the hyperbolic nature of the function describing the force of the desires: the two curves describing an earlier and a later reward cross: after this preference reversal, it becomes rational to take the earlier reward, even if its value is smaller [26], quod erat demonstrandum.

\section{A second aspect of chronicity: temporal horizon}

The application of this conceptual framework has considerable support in the field of addiction (as reviewed $[9,11,16$, $19,27,28])$. Is it relevant to the general issue of patient nonadherence to their medical prescriptions? Attempts to find an association between the degree of impulsivity, determined by a monetary choice, on the one hand, and health behaviours such as vaccination against influenza, adherence to antihypertensive or cholesterol-lowering medications on the other hand, were found to be negative in one study [29].

Such negative data do not, however, rule out an association between time preference and adherence to long-term therapies. The association may be indirect. First, there is considerable evidence that time preference is associated with smoking status (reviewed by Perry and

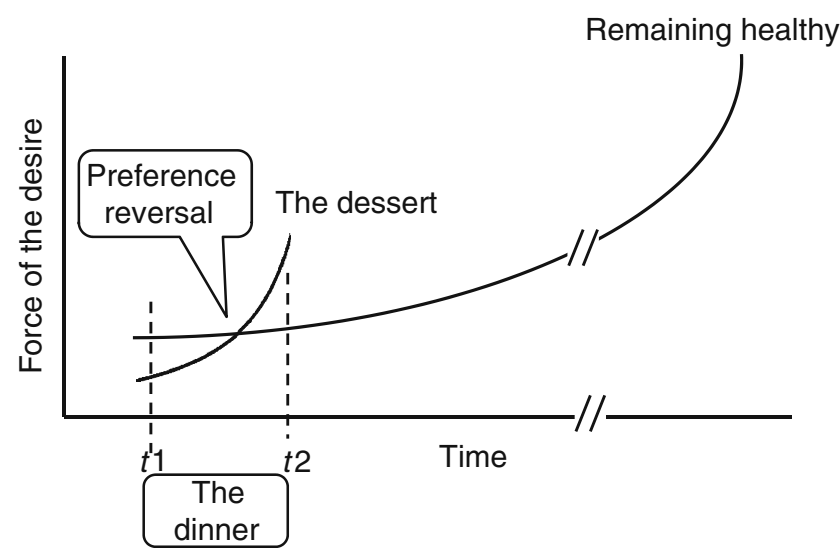

Fig. 2 Intertemporal choice. I enter a restaurant $(t 1)$; the force of my desire to follow my diet in order to remain healthy is higher than my desire to order the dessert. By the end of the dinner $(t 2)$, the curves describing the force of my desires have crossed, producing a preference reversal [26]. Rationally, I order the dessert 
Carroll [16]), which is itself associated with patient adherence: for instance, diabetic patients who smoke are less adherent to recommendations concerning bloodglucose monitoring and exercise and skip more medical appointments than non-smokers [30]; by contrast nonsmokers accept a complex treatment more easily [31]. Smokers are less adherent to bisphosphonate therapy [32]. Similarly, alcohol consumption is a marker for poorer adherence to diabetes self-care behaviours [33].

Further, and in the same vein, adherence to medication (a bisphosphonate or a statin) was found in two studies to be associated with the use of preventive health services, such as prostate-specific antigen tests, faecal occult blood tests, screening mammography or influenza and pneumococcal vaccination $[32,34]$. Another study found an association between future preference, assessed by a four-item questionnaire, and the frequency of use of genetic counselling for BRCA1/2 testing (used to obtain information about future risk of breast and ovarian cancer) and mammography screening. The preference for future outcomes, determined through the four-item time-preference scale, was inversely correlated with monetary impulsivity and with cigarette smoking [35].

This suggests that impatience, which can be evaluated through the monetary choice procedure, is a part of a more general construct, described as temporal horizon, which, according to Bickel et al. [36], describes the window in time in which an individual is capable of perceiving and planning. In a recent study, temporal horizon was evaluated by using a method initially described by Wallace [37], based on two types of questions: for instance, the first question asks participants to write a list of ten events that will occur in their lives and to indicate the age at which they would expect each event to occur. The second type of question asks participants to write endings to short stories and to indicate the duration of the story. Both measures provide estimates of how far into the future a person typically plans. Participants in the study also completed a monetary discounting task. Overall, participants with lower discounting rates tended to provide longer time estimates for stories than those with higher discounting rates. Smoking women were found to have a shorter temporal horizon than their non-smoking counterparts [38].

This type of investigation has not, so far as I am aware, been performed in relation to adherence to medication or other health behaviours. However, this concept of temporal horizon may explain why people who live in poverty or any form of social deprivation and uncertainty, who have a shortened life expectancy, or who have other constraints upon their future expectations, may very reasonably opt for the short-term benefit and, therefore, be non-adherent to long-term therapies. In other words, the impatience genotype might also be a phenotype.

\section{Discussion}

The main aim of this article was to propose the hypothesis that adherence to health behaviours, like addiction, is related in part to the relationship that patients have to temporality. According to this hypothesis presented, non-adherent patients are by and large less capable of giving priority to the future. They can manifest this incapacity either on a daily basis in relation to the short-term reward of non-adherence (see Fig. 2), or in a broader perspective, because their temporal horizon is limited. This incapacity may even have a partly genetic basis, such that some individuals have an 'impatience genotype' leading to addiction, or to nonadherence to long-term therapies, or both.

This hypothesis is consistent with: (1) the frequent association between several manifestations of nonadherence and smoking and alcohol habits: for instance, smoking and excessive alcohol consumption are independent predictors of low practice of self-monitoring of blood glucose in diabetic patients [39]; (2) the effect of young age on non-adherence in chronic diseases [7]; (3) the frequency of non-adherence in teenagers (an experimental study showed that adolescents and people in their twenties have more difficulties in finding similarities between them now and them in the future than older people [40]); (4) the fact that the level of maturity is associated with adherence to immunosuppressive drugs in adolescent and young adults following heart transplantation [41]; (5) data from fMRI studies, providing the evidence that the balance between frontal and limbic circuitries is relatively late maturing during the brain development from childhood to adult age [42, 43]: it is tempting (even if hazardous) to see an explanation of a risk in teenagers, not only for addiction, but also for poor adherence; (6) the effect of social deprivation on non-adherence to medication [44]: a shorter temporal horizon was found to be associated to a lower income [38]; (7) the effect of education on adherence to medication and other health behaviours [45]: a stronger future orientation of women, who asked more frequently for BRCA1/2 screening and mammography, was seen in women who had higher levels of education [35]; and finally (8), this explanation may represent a common link leading to a clustering of preventive behaviours in some individuals, this concept of 'healthy adherer' explaining the puzzling observation that adherence to a placebo is associated with a decrease in mortality [46].

If the hypothesis presented in this article is correct, we doctors should spend more time asking our patients how they consider their future (rather than focusing on their history), since this may determine their long-term adherence to medical advice and other health-related behaviours. We should next tailor our therapies and explanations according to this psychological dimension, for instance pointing out to 
an 'impatient patient' some immediate and concrete advantages of being adherent, rather than the abstract and longterm objective of 'avoiding complications'.

Certainly, patients are not computers. However, when they have to make a choice between different possible options, they will evaluate different types and sources of medical information, and will 'weight' them in accordance with this evaluation. The aim of this paper was to stress the point that impatience may represent a trait of character that can have a powerful impact on this rational choice, leading sometimes to a decision which may seem to be irrational, such as non-adherence to immunosuppressive drugs of heart-transplanted patients: this 'irrationality' may have a neurophysiological support [47]. Since it may be difficult, or impossible, or even unethical, to want to change peoples' characters, the art of medicine may consist in offering advice that is not only objectively sound but is also adapted to the patient's own priorities, understanding of the situation, and character.

Acknowledgement The author is grateful to E.A.M. Gale for his helpful suggestions.

Duality of interest The author declares that there is no duality of interest associated with this manuscript.

\section{References}

1. Report WHO (2003) Adherence to long term therapies, evidence for action. World Health Organization Publications, Geneva

2. Lawrence DB, Ragucci KR, Long LB, Parris BS, Helfer LA (2006) Relationship of oral antihyperglycemic (sulfonylurea or metformin) medication adherence and hemoglobin A1c goal attainment for HMO patients enrolled in a diabetes disease management program. J Manag Care Pharm 12:466-471

3. Rozenfeld Y, Hunt JS, Plauschinat C, Wong KS (2008) Oral antidiabetic medication adherence and glycemic control in managed care. Am J Manag Care 14:71-75

4. Ho PM, Rumsfeld JS, Masoudi FA et al (2006) Effect of medication nonadherence on hospitalization and mortality among patients with diabetes mellitus. Arch Intern Med 166:1836-1841

5. Lee WC, Balu S, Cobden D, Joshi AV, Pashos CL (2006) Prevalence and economic consequences of medication adherence in diabetes: a systematic literature review. Manag Care Interface 19:31-41

6. Sokol MC, McGuigan KA, Verbrugge RR, Epstein RS (2005) Impact of medication adherence on hospitalization risk and healthcare cost. Med Care 43:521-530

7. Briesacher BA, Andrade SE, Fouayzi H, Chan KA (2008) Comparison of drug adherence rates among patients with seven different medical conditions. Pharmacotherapy 28:437-443

8. Harrold LR, Andrade SE, Briesacher BA et al (2009) Adherence with urate-lowering therapies for the treatment of gout. Arthritis Res Ther 11:R46

9. Kalenscher T, Pennartz C (2008) Is a bird in the hand worth two in the future? The neuroeconomics of intertemporal decisionmaking. Prog Neurobiol 84:284-315

10. Rachlin H, Raineri A, Cross D (1991) Subjective probability and delay. J Exp Anal Behav 55:233-244

11. Bickel WK, Johnson MW (2003) Delay discounting: a fundamental behavioural process of drug dependence. In: Loewenstein
G, Read D, Baumeister RF (eds) Time and decision. Russel Sage Foundation, New York, pp 419-440

12. Mischel W, Shoda Y, Rodriguez ML (1989) Delay of gratification in children. Science 244:933-938

13. Elster J, Skog OJ (1999) Getting hooked, rationality and addiction. Cambridge University Press, Cambridge

14. Johnson MW, Bickel WK, Baker F (2007) Moderate drug use and delay discounting: a comparison of heavy, light, and never smokers. Exp Clin Psychopharmacol 15:187-194

15. Mitchell JM, Fields HL, D'Esposito M, Boettiger CA (2005) Impulsive discounting in alcoholics. Alcohol Clin Exp Res 29:2158-2169

16. Perry JL, Carroll ME (2008) The role of impulsive behavior in drug abuse. Psychopharmacology 200:1-26

17. Takahashi T, Oono H, Inoue $\mathrm{T}$ et al (2008) Depressive patients are more impulsive and inconsistent in intertemporal choice behavior for monetary gain and loss than healthy subjects - an analysis based on Tsallis' statistics. Neuro Endocrinol Lett 29:351-358

18. Weller RE, Cook EW III, Aswar KB, Cox JE (2008) Obese women show greater delay discounting than healthy-weight women. Appetite 51:563-569

19. Bickel WK, Miller ML, Yi R, Kowal BP, Lindquist DM, Pitcock JA (2007) Behavioral and neuroeconomics of drug addiction: competing neural systems and temporal discounting processes. Drug Alcohol Depend 90(Suppl 1):S85-S91

20. Boettiger CA, Mitchell JM, Tavares VC et al (2007) Immediate reward bias in humans: fronto-parietal networks and a role for the catechol- $O$-methyltransferase $158^{\mathrm{val} / \mathrm{val}}$ genotype. J Neurosci 27:14383-14391

21. Manuck SB, Flory JD, Ferrell RE, Mann JJ, Muldoon MF (2000) A regulatory polymorphism of the monoamine oxidase-A gene may be associated with variability in aggression, impulsivity, and central nervous system serotonergic responsivity. Psychiatry Res 95:9-23

22. Shaw P, Wallace GL, Addington A, Evans A, Rapoport J, Giedd JN (2009) Effects of the Val158Met catechol- $O$-methyltransferase polymorphism on cortical structure in children and adolescents. Mol Psychiatry 14:348-349

23. Elster J (1977) Ulysses and the Sirens: a theory of imperfect rationality. Soc Sci Inf 16:469-526

24. Southam L, Soranzo N, Montgomery SB et al (2009) Is the thrifty genotype hypothesis supported by evidence based on confirmed type 2 diabetes- and obesity-susceptibility variants? Diabetologia 52:1846-1851

25. Bickel WK, Pitcock JA, Yi R, Angtuaco EJ (2009) Congruence of BOLD response across intertemporal choice conditions: fictive and real money gains and losses. J Neurosci 29:8839-8846

26. Ainslie G (2001) Breakdown of will. Cambridge University Press, New York

27. Reynolds B (2006) A review of delay-discounting research with humans: relation to drug use and gambling. Behav Pharmacol $17: 661-667$

28. Monterosso J, Ainslie G (2007) The behavioral economics of will in recovery from addiction. Drug Alcohol Depend 90(Suppl 1): S100-S111

29. Chapman GB, Brewer NT, Coups EJ, Browlee S, Leventhal H, Leventhal EA (2001) Value for the future and preventive health behavior. J Exp Psychol Appl 7:235-250

30. Solberg LI, Boyle RG, McCarty M, Asche SE, Thoele MJ (2004) Diabetic patients who smoke: are they different? Ann Fam Med 2:26-32

31. Perros P, Deary IJ, Frier BM (1998) Factors influencing preference of insulin regimen in people with type 1 (insulindependent) diabetes. Diabet Res Clin Pract 39:23-29

32. Curtis JR, Xi J, Westfall AO et al (2009) Improving the prediction of medication compliance: the example of bisphosphonates for osteoporosis. Med Care 47:334-341 
33. Ahmed AT, Karter AJ, Liu J (2006) Alcohol consumption is inversely associated with adherence to diabetes self-care behaviours. Diabet Med 23:795-802

34. Brookhart MA, Patrick AR, Dormuth C et al (2007) Adherence to lipid-lowering therapy and the use of preventive health services: an investigation of the healthy user effect. Am J Epidemiol 166:348-354

35. Gurmankin Levy A, Micco E, Putt M, Armstong K (2006) Value for the future and breast cancer-preventive health behaviour. Cancer Epidemiol Biomarkers Prev 15:955-960

36. Bickel WK, Yi R, Kowal BP, Gatchalian KM (2008) Cigarette smokers discount past and future rewards symmetrically and more than controls: is discounting a measure of impulsivity? Drug Alcohol Depend 96:256-262

37. Wallace M (1956) Future time perspective in schizophrenia. J Abnorm Psychology 52:240-245

38. Jones BA, Landes RD, Yi R, Bickel WK (2009) Temporal horizon: modulation by smoking status and gender. Drug Alcohol Depend 104(Suppl 1):S87-S93

39. Karter AJ, Ferrara A, Darbinian JA, Ackerson LM, Selby JV (2000) Self-monitoring of blood glucose: language and financial barriers in a managed care population with diabetes. Diabetes Care 23:477-483
40. Frederick S (2003) Time preference and personal identity. In: Loewenstein G, Read D, Baumeister RF (eds) Time and decision. Russel Sage Foundation, New York, pp 89-113

41. Stilley CS, Lawrence K, Bender A, Olshansky E, Webber SA, Dew MA (2006) Maturity and adherence in adolescent and young adult heart recipients. Pediatr Transplant 10:323-330

42. Giedd JN (2004) Adolescent brain development: vulnerabilities and opportunities. Ann N Y Acad Sci 1021:77-85

43. Galvan A, Hare TA, Parra CE et al (2006) Earlier development of the accumbens relative to orbitofrontal cortex might underlie risktaking behavior in adolescents. J Neurosci 26:6885-6892

44. Wamala S, Merlo J, Bostrom G, Hogstedt C, Agren G (2007) Socioeconomic disadvantage and primary non-adherence with medication in Sweden. Int J Qual Health Care 19:134-140

45. Keller DL, Wright J, Pace HA (2008) Impact of health literacy on health outcomes in ambulatory care patients: a systematic review. Ann Pharmacother 42:1272-1281

46. Simpson SH, Eurich DT, Majumdar SR et al (2006) A metaanalysis of the association between adherence to drug therapy and mortality. BMJ 333:15

47. Kalis A, Mojzisch A, Schweizer TS, Kaiser S (2008) Weakness of will, akrasia, and the neuropsychiatry of decision making: an interdisciplinary perspective. Cogn Affect Behav Neurosci 8:402-417 